\section{Is beta 2 urinary microglobulin a biomarker of topographical discrimination between high and low urinary tract infection?}

\author{
Richard Loumingou* \\ Nephrology Service of the C.H.U. of Brazzaville, Republic of the Congo
}

\section{Introduction}

Urinary tract infections are common affection in the general population.

Diagnosis is often easy in the presence of evocative clinical signs.

The diagnosis of urinary tract infection is evoked in the presence of an uropathogenic germ in the urine in sufficient quantity associated with urinary signs. The presence of lower back pain, chills, fever higher than $39^{\circ}$ is suggestive of a high urinary tract infection localized in the kidney, the absence of fever associated with dysuria is suggestive of low urinary tract infection localized in the bladder.

Topographic diagnosis is sometimes difficult, especially in children, due to the existence of various clinical forms.

The distinction between high and low urinary tract infections is useful; this distinction has important therapeutic consequences and prognosis.

Early and appropriate treatment of acute pyelonephritis is essential because it is associated with a high risk of kidney scarring from high blood pressure and chronic kidney failure [1].

The biomarkers used (procalcitonin, interleukins 18) and radiological investigations (scintigraphy, cystography) have less specificity [2,3] and above all limited accessibility in Africa. The risk of misdiagnosis, late treatment of a possible masked high urinary tract infection is not negligible.

The purpose of this work was to suggest the probable role of urinary beta 2 microglobulin as a biomarker likely to represent by its variations an indicator of renal, tubulointerstitial parenchymatous lesions during high urinary tract infections.

\author{
More Information \\ *Address for Correspondence: Richard \\ Loumingou, Nephrology Service of the C.H.U. \\ of Brazzaville, 1 Boulevard Auxence Ickonga, \\ Republic of the Congo, Tel: +24206660 33 69; \\ Email: richardloumingou@gmail.com \\ Submitted: 21 April 2020 \\ Approved: 27 April 2020 \\ Published: 28 April 2020 \\ How to cite this article: Loumingou R. \\ Is beta 2 urinary microglobulin a biomarker of \\ topographical discrimination between high and \\ low urinary tract infection? J Clini Nephrol. 2020; \\ 4: 020-021. \\ DOI: 10.29328/journal.jcn. 1001053 \\ Copyright: (c) 2020 Loumingou R. This is \\ an open access article distributed under the \\ Creative Commons Attribution License, which \\ permits unrestricted use, distribution, and \\ reproduction in any medium, provided the \\ original work is properly cited. \\ Check for updates \\ OPEN ACCESS
}

The purpose was the early diagnosis and appropriate treatment of high urinary tract infections in our environment.

\section{Materials and methods}

We carried out a cross-sectional study from January to December 2019 in the Nephrology Consultation and Hospitalization Department at the Brazzaville Hospital and University Center (CHU).

We included in this study, patients who presented clinical and biological signs suggestive of low or high urinary tract infection. The evaluation criteria were for low urinary tract infection: moderate fever below $38.5^{\circ}$ or absence of fever, presence of pollakiuria, urination burns and hematuria. High urinary tract infection was evoked in the presence of high fever $39-40^{\circ}$, lower back pain, hyperleucocytosis, an acceleration of the rate of sedimentation and an increase in C-reactive protein. For all patients, cytobacteriological examination of urine was performed; a consistent review of KASS of $10^{5}$ or more was considered positive.

We excluded from the study sickle cell patients, those receiving ongoing nephrotoxic treatments (aminosides, sulfamides, nonsteroidal anti-inflammatory drugs, anticancers) and HIV infection. All patients hospitalized for another reason, for another pathology were also excluded from the study. 
Beta 2 microglobulin was positive if greater than 0.28 $\mathrm{mg} / \mathrm{g}$ of urinary creatinine. The data analysis was performed on the EPI Info software and entered on the Word Software.

\section{Results}

70 patients were selected the average age was 32 years with extremes of 14 - 50 years, there were 56 women, 14 men.

All patients had a positive urine culture. CRP was not performed in all patients. 25 patients were suspected of upper urinary tract infection with a clinical picture associating fever $>39^{\circ}$, lower back pain, sometimes chills. 35 patients were suspected of having lower urinary tract infections with a clinical picture associating a temperature greater than or equal to $37.5^{\circ}$ and dysuria. The urinary microalbuminuria B2 assay was performed in all patients.

\begin{tabular}{|c|c|c|}
\hline $\begin{array}{c}\text { B2 urinary } \\
\text { microglobulin }\end{array}$ & $\begin{array}{c}\text { Suspect UI low } \\
n=35 \\
\text { (Cytitis) }\end{array}$ & $\begin{array}{c}\text { Suspect UI high } \\
n=25 \\
\text { (Pyelonephritis) }\end{array}$ \\
\hline Increased & $n=2$ & $n=22$ \\
\hline Normal & $n=33$ & $n=3$ \\
\hline
\end{tabular}

\section{Discussion}

The classic topographic diagnosis between high or low urinary tract infections is based on clinical, biological or radiological criteria. However the pitfalls are numerous, the low urinary infection can be complicated from high urinary tract infection by the existence of a urethral vesico reflux. The infection can also cause reflux by ascending spread of the low urinary tract infection from the bladder to the renal tissue. Reflux, a congenital abnormality of the uretero-bladder junction, is often caused by the urinary tract infection itself [4]. High urinary tract infection is linked to colonization of the renal parenchyma by germs, leading to predominant tubular interstitial lesions. Tubular dysfunction leads to a decrease in the reabsorption of tubular proteins leading to an increase in their urinary excretion. Beta 2 urinary microglobulin is a tubulo-protein, augmented in inflammatory and infectious syndromes, during certain cancers [5]. Despite intraindividual variability and instability in acidic urine, the increase in the level of B2 microglobulin generally reflects renal parenchymal damage. In our study all patients had documented urinary tract infection. Patients with suspected lower urinary tract infection did not have an increase of urinary microglubulin B2 levels. The increase of urinary excretion of B2 microglobulin observed in some patients can be explained by a decrease in the proximal reabsorption of B2 microglobulin secondary to infectious damage to the renal parenchyma.

We suggest the hypothesis that an increase in beta 2 urinary microglobulin may be the witness of a renal tubular parenchymatous disease suggesting a high urinary tract infection.

A normal level of Beta 2 microglobulin in a suspected urinary tract infection may be compatible with a cured high urinary tract infection or a low location of a urinary tract infection.

\section{Conclusion}

Beta 2 urinary microglobulin appears to be a biomarker of topographical discrimination between high and low urinary tract infection. Larger studies are needed to confirm or disprove this hypothesis.

The correlation with urinary tract infection biomarkers used in common practice may be the subject of further studies.

\section{References}

1. Keren R. Imaging and treatment strategies for children after first urinary infection. Curr open Pediatr. 2007, 19: 705 - 710.

PubMed: https://www.ncbi.nlm.nih.gov/pubmed/18025941

2. Bacchetta J, Hees L, Demède D, Gillet $Y$, Cochat $P$. Infections urinaires de l'enfant. Revue du praticien. Med. Gen. 2013, 27: 9 - 11.

3. Leroy S, Romanello C, Galetto-Lacour A, Smolkin V, et al. Procalcitonin to reduce the number of unnecessary cystographies in children with a urinary tract infection : A European validation study. J Pediatr. 2007, 150: 89 - 95.

PubMed: https://www.ncbi.nlm.nih.gov/pubmed/17188622

4. William G, Flecther JT, Alexander SI, Craig JC. Vesicoureteral reflux. J Am Soc Nephrol. 2008, 19: 847 - 62.

PubMed: https://www.ncbi.nlm.nih.gov/pubmed/18322164

5. Snahnicanova Z, Kasubova I, Kalman M, Grendar M, Mikolajcik P, et al. Genetic and epigenetic analysis of the beta-2-microglobulin gene in microsatellite instable colorectal cancer. Clinic Exp Med. 2020, 20: 87 - 95.

PubMed: https://www.ncbi.nlm.nih.gov/pubmed/31853669 